\title{
Echogenic Adnexal Masses Associated with First-Trimester Pregnancy: Sonographic Appearance and Clinical Significance
}

\author{
David R. Pennes, MD, Richard A. Bowerman, MD, and Terry M. Silver, MD
}

\begin{abstract}
In a retrospective survey of a large obstetrical ultrasound experience, 10 echogenic adnexal masses in nine patients with a coexistent intrauterine pregnancy were detected and analyzed. Definitive follow-up data available for seven of the nine patients disclosed three ovarian teratomas, two hemorrhagic corpus luteum cysts, one endometrioma, one inflammatory mass, and one colonic pseudomass. In one additional patient, an echogenic ectopic pregnancy with an intrauterine pseudogestational sac simulated the above entities. Conservative management with follow-up sonography is generally indicated for echogenic masses coexistent with first-trimester intrauterine pregnancies. Indexing Words: Ultrasound, pregnancy - Mass, adnexa - Dermoid · Cyst, corpus luteum
\end{abstract}

Sonolucent masses in the adnexae are a common finding in first-trimester obstetrical ultrasound examinations and are almost always corpus luteum cysts. ${ }^{1}$ An increase in the size of these lesions as pregnancy progresses supports the diagnosis of a corpus luteum cyst, since the natural history of such cysts is to enlarge during the first trimester before diminishing in size later in pregnancy and eventually disappearing.

Echogenic adnexal masses coexistent with pregnancy are much less common, and their presence may create management dilemmas for the obstetrician. The rarity of coexistent echogenic adnexal masses and early intrauterine pregnancy and uncertainty regarding their clinical significance prompted us to retrospectively study our experience and determine their nature and outcome.

\section{MATERIALS AND METHODS}

All obstetrical sonograms (approximately 8000 examinations) performed at the University of Michigan Medical Center from January, 1978, to

From the Department of Radiology, University of Michigan Hospitals, Ann Arbor, MI. Manuscript received March 20, 1984; revised manuscript accepted September 6, 1984. For reprints contact David R. Pennes, MD, Department of Radiology, Box 13, University of Michigan Hospitals, Ann Arbor, MI 48109 .
December, 1983, were reviewed. Within this study population, nine patients with 10 echogenic adnexal masses and coexistent intrauterine pregnancies were identified, and this group was the subject of this study. Sonography was performed using commercially available gray-scale B-mode static scanners as well as real-time mechanical sector scanners employing $3.0-, 3.5-$, or $5-\mathrm{MHz}$ transducers.

Each of the echogenic adnexal masses was analyzed by the following criteria: (1) size, (2) shape, (3) location, (4) effect on adjacent structures, (5) echogenicity, and (6) sound transmission characteristics.

\section{RESULTS}

Of the nine patients with echogenic adnexal masses and coexistent pregnancies, the nature of the masses was determined in seven (eight masses). All seven patients with confirmation were in the first trimester of pregnancy at the time of initial sonography, based on crown-rump length and gestational sac diameter measurements. The two patients whose masses remain unconfirmed were detected at 6 and 12 weeks of gestational age, respectively. Of these two patients, one was lost to follow-up, and the other remains asymptomatic without further evaluation 2 years later. All 10 adnexal masses were 
TABLE 1

Patient Data

\begin{tabular}{|c|c|c|c|c|c|c|c|c|}
\hline & \multicolumn{8}{|c|}{ Patient Number } \\
\hline & 1 & 2 & 3 & $4 a$ & $4 b$ & 5 & 6 & 7 \\
\hline $\begin{array}{l}\text { Gestational age } \\
\text { (weeks) }\end{array}$ & 8 & 4 & 7 & 7 & 7 & 7 & 8 & 6 \\
\hline Location & & & & & & & & \\
\hline $\begin{array}{l}\text { Right, } 1 \\
\text { Left, } 2 \\
\text { Cul de sac, } 3\end{array}$ & 1 & 1 & 2 & 1 & 2 & 3 & 2 & 1 \\
\hline $\begin{array}{l}\text { Size }(\mathrm{cm}) \\
\text { Shape }\end{array}$ & 4 & 4 & 4.5 & 4 & 2.8 & 6.5 & 4 & 6 \\
\hline $\begin{array}{l}\text { Sperical, } 1 \\
\text { Ovoid, } 2\end{array}$ & 1 & 1 & 2 & 1 & 1 & 2 & 1 & 2 \\
\hline $\begin{array}{l}\text { Indenting adjacent } \\
\text { structures } \\
\text { Echotexture }\end{array}$ & + & - & - & + & + & + & - & - \\
\hline $\begin{array}{l}\text { Homogeneous, } 1 \\
\text { Heterogeneous, } 2\end{array}$ & 1 & 2 & 2 & 1 & 1 & 2 & 1 & 2 \\
\hline $\begin{array}{l}\text { Enhancement, } 1 \\
\text { Shadowing, } 2 \\
\text { Neither, } 3\end{array}$ & 3 & 2 & 1 & 2 & 2 & 3 & 3 & 1 \\
\hline $\begin{array}{l}\text { Diagnostic method } \\
\text { Laparotomy, } 1 \\
\text { Enema, } 2 \\
\text { Clinical F/U, } 3 \\
\text { Laparoscopy, } 4\end{array}$ & 1 & 2 & 3 & 1 & 1 & 1 & 3,4 & 3,4 \\
\hline $\begin{array}{l}\text { Final diagnosis } \\
\text { Dermoid, } 1 \\
\text { Corpus luteum }\end{array}$ & & & & & & & & \\
\hline $\begin{array}{l}\text { cyst, } 2 \\
\text { Endometrioma, } 3 \\
\text { Colon, } 4 \\
\text { Inflammatory } \\
\text { mass, } 5\end{array}$ & 1 & 4 & 2 & 1 & 1 & 3 & 5 & 2 \\
\hline
\end{tabular}

discovered on the initial sonographic examination.

The sonographic and clinical data are summarized in Table 1. The basis for diagnosis was laparotomy (three patients), laparoscopic and sonographic follow-up (two patients), and sonographic follow-up (two patients).

\section{Clinical Results}

In five of the nine patients, the masses were discovered as incidental findings. The other four were referred for sonography because of either an adnexal mass or tenderness elicited on physical examination.

None of the nine patients with adnexal masses underwent laparotomy during pregnancy, and none had complications that could definitely be attributed to the presence of the mass itself. Three delivered term pregnancies, two spontaneously aborted, three pregnancies were terminated, and the result of the ninth pregnancy is unknown.

\section{Sonographic Results}

In those patients with confirmation of the sonographic findings, the masses ranged in size from $2.8 \mathrm{~cm}$ to $6.5 \mathrm{~cm}$, with an average size of $4.5 \mathrm{~cm}$. The masses were ovoid or spherical, and several demonstrated a mass effect by indenting the urinary bladder (Fig. 1). All of the masses were echogenic, although the texture of the echogenicity (coarse or fine, homogeneous or heterogeneous) varied in individual cases. One adnexal mass (rectosigmoid colon) had focal areas of hyperechogenicity with acoustic shadowing, suggesting calcification or gas (Fig. 2). Enhanced sound transmission (Fig. 3) was present in two cases despite marked internal echogenicity usually associated with solid masses.

\section{Pathologic Results}

Ovarian teratomas accounted for three of the echogenic adnexal masses, and in one patient these were bilateral (Fig. 4). In two cases, the adnexal masses were hemorrhagic corpus luteum cysts (Fig. 3). The other three masses included an endometrioma (Fig. 5), an inflammatory mass involving the ovary, and a colonic pseudomass (Fig. 2).

\section{DISCUSSION}

Our data indicate that the presence of an echogenic adnexal mass coexistent with an early in-

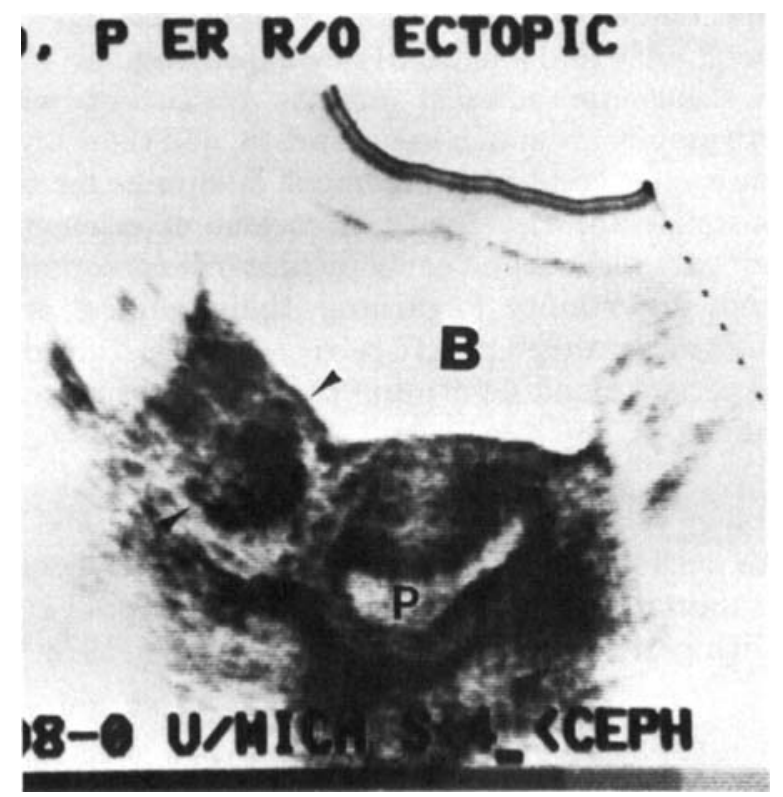

FIGURE 1. Patient 1. Ovarian teratoma, transverse scan. Fourcentimeter hyperechoic right adnexal mass (arrowheads) adjacent to an 8-week intrauterine pregnancy (P). Minimal extrinsic flattening of the urinary bladder (B). 


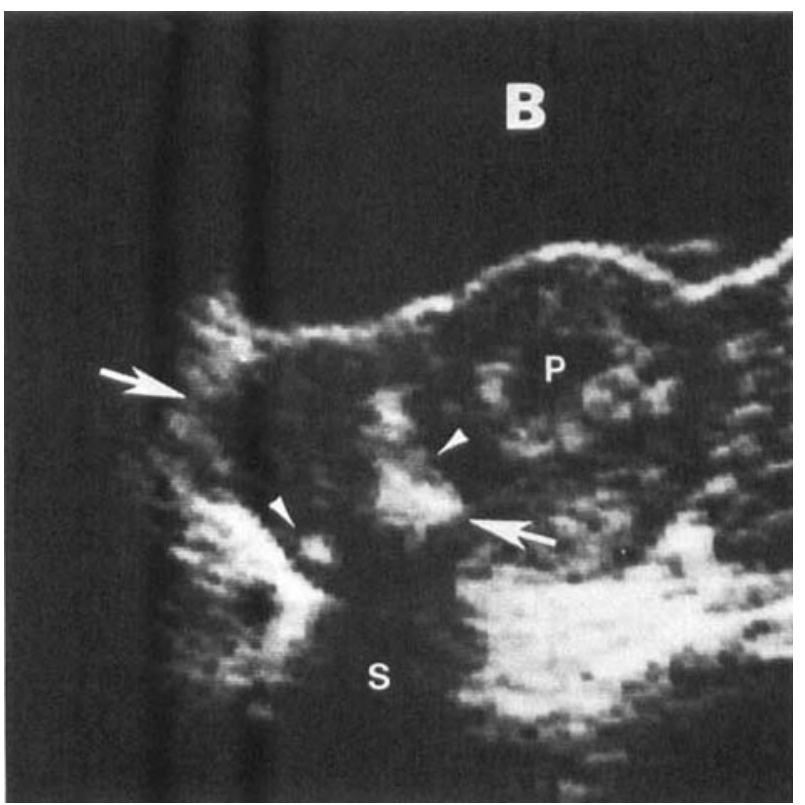

FIGURE 2. Patient 2. Rectosigmoid colon simulating right adnexal mass, transverse scan. Four-centimeter solid-appearing right adnexal mass (arrows) containing discrete hyperechoic foci (arrowheads), some of which produce acoustic shadowing (S). Note absence of extrinsic impression on the urinary bladder wall (B). P, 7-week intrauterine pregnancy.

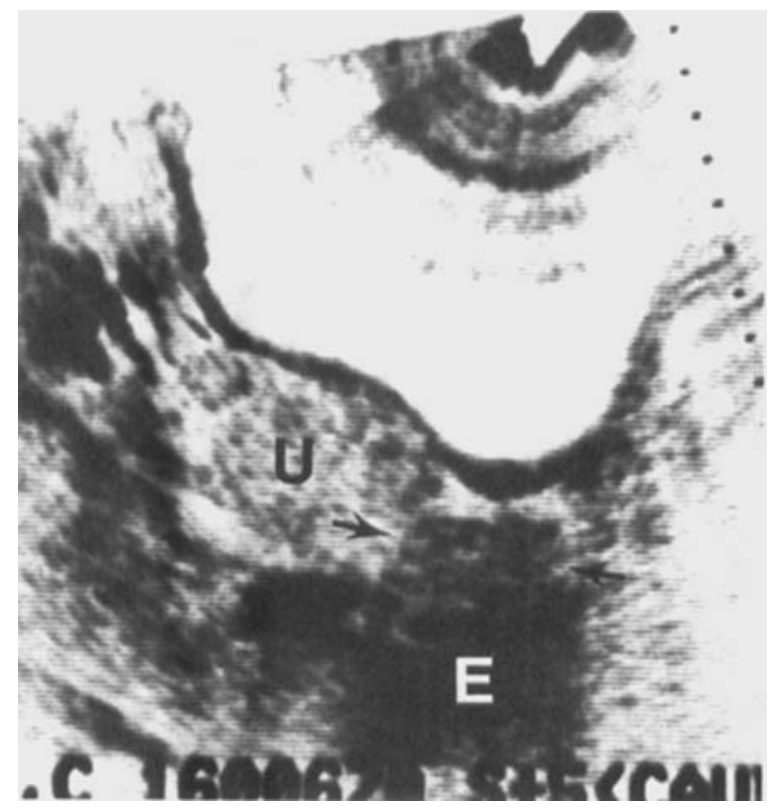

FIGURE 3. Patient 3. Hemorrhagic corpus luteum cyst. Transverse scan through the lower uterus (U) shows a markedly echogenic left adnexal mass (arrows) with enhanced sound transmission (E).

trauterine pregnancy is rare, with an incidence of approximately $1 / 800$. The primary concerns about such masses include possible malignancy, complications directly related to the mass itself, and possible ectopic pregnancy. The incidence of ovarian malignancy during pregnancy is low, occurring with a frequency of one per 9000-25,000 de- liveries. ${ }^{3}$ This incidence is similar to that in an age-matched, nonpregnant population. ${ }^{4}$ Of all ovarian neoplasms, more than $90 \%$ are teratomas and benign cystadenomas, with malignancies accounting for only approximately $2-6 \% .^{4-6}$

Complications related to the mass itself include torsion, hemorrhage, and obstruction of the birth canal. ${ }^{4}$ The probability of torsion of an adnexal mass is increased during pregnancy, especially during labor or the postpartum period. ${ }^{4}$

In our experience, an echogenic adnexal mass most often represented a teratoma or hemorrhagic corpus luteum cyst. Occasionally, the diagnosis of an adnexal mass such as a teratoma may be suggested with a high degree of certainty on the basis of certain characteristic sonographic features such as acoustic shadowing (Fig. 4). In general, however, the sonographic appearances are less specific, and other clinical parameters, diagnostic procedures, or surgery are frequently necessary to determine the nature of an individual mass.

Ovarian teratomas may have a spectrum of sonographic appearances, reflecting their varied histologic composition. Although a highly specific sonographic finding of dense calcification (i.e., teeth) in a teratoma suggests the diagnosis, ${ }^{7,8}$ none of the three teratomas in our series had this feature.

Endometriomas can appear as solid, cystic, polycystic, septated, or mixed solid and cystic lesions $^{8-11}$ and can be confused sonographically with an ectopic pregnancy or a tuboovarian abscess. ${ }^{9}$ In general, solid-appearing endometriomas demonstrate acoustic enhancement, and differentiation from solid ovarian masses should not be difficult since the latter are frequently more heterogeneous and echogenic and demonstrate sound attenuation. ${ }^{9}$

Hemorrhagic corpus luteum cysts also have a variety of sonographic appearances and can appear as cystic, septated, or echogenic masses. ${ }^{12,13}$ As with endometriomas, enhanced sound transmission (Fig. 3) indicates the fluid nature of such masses.

The misinterpretation of a bowel loop for an abnormal mass is a pitfall in pelvic sonography. The use of a water enema during real-time evaluation to differentiate between bowel and an abnormal mass is sometimes of value, ${ }^{14,15}$ although real-time examination of the mass in question alone often suffices, obviating the need for an enema. In one of our cases (Fig. 2), the appearance of the bowel remained remarkably constant on three successive sonograms performed over a 4-week interval. In this case, an enema was re- 

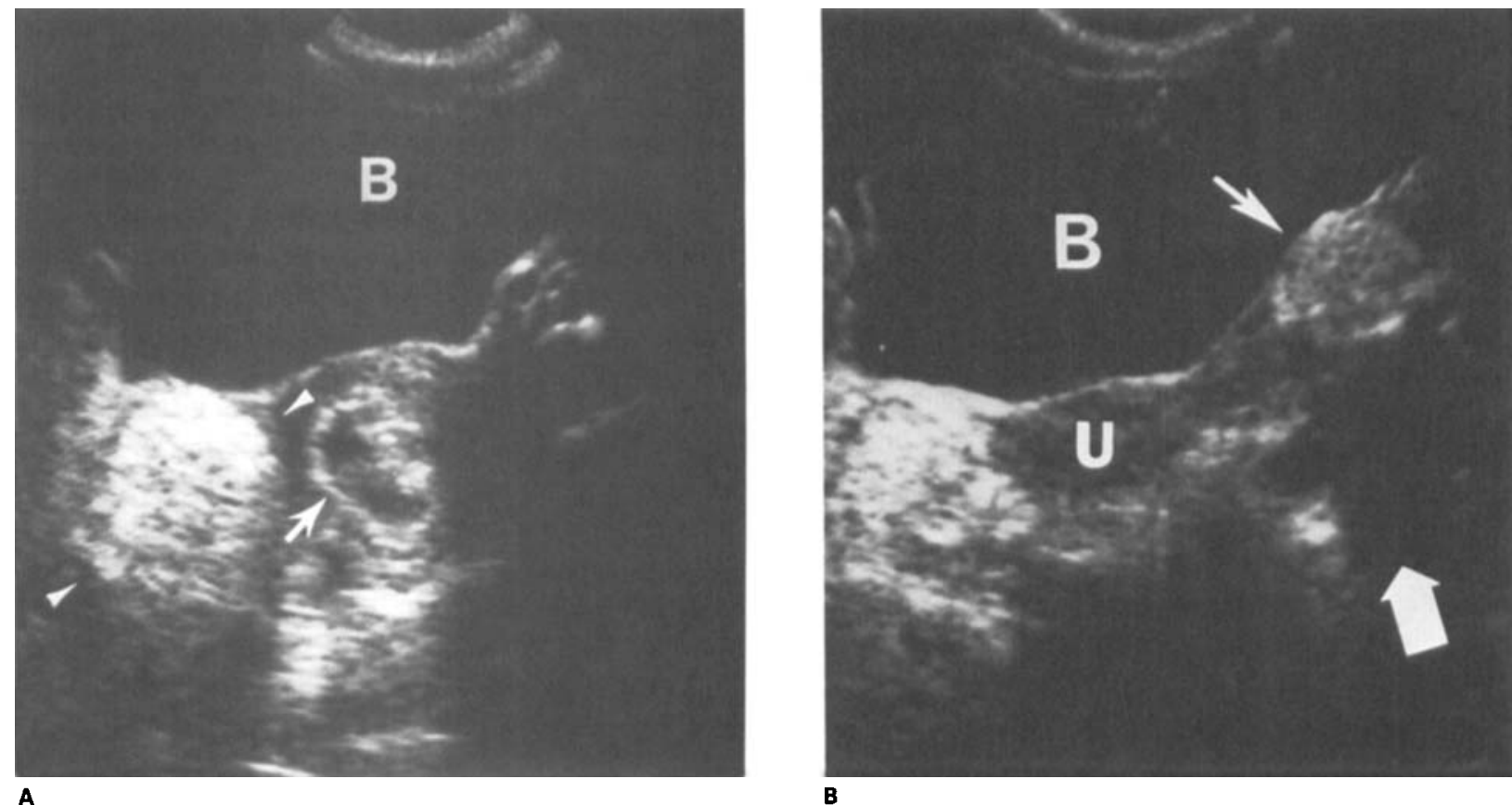

A B

FIGURE 4. Patient 4. Bilateral ovarian teratomas. (A) Transverse scan: 4-cm echogenic right adnexal mass (arrowheads) with acoustic shadowing. Seven-week intrauterine pregnancy (arrow). B, bladder. (B) Transverse oblique sonogram through the uterine fundus (U) shows a 2.8-cm echogenic left adnexal mass (small arrow) producing a prominent acoustic shadow (large arrow). Note impression on the left side of the urinary bladder (B).

quired to define the true nature of the "mass" as colon.

An inflammatory mass involving the left ovary (patient 6) had been noted at laparoscopy 9 months before pregnancy. The laparoscopic appearance was consistent with adhesions involving omentum and broad ligament structures, presum-

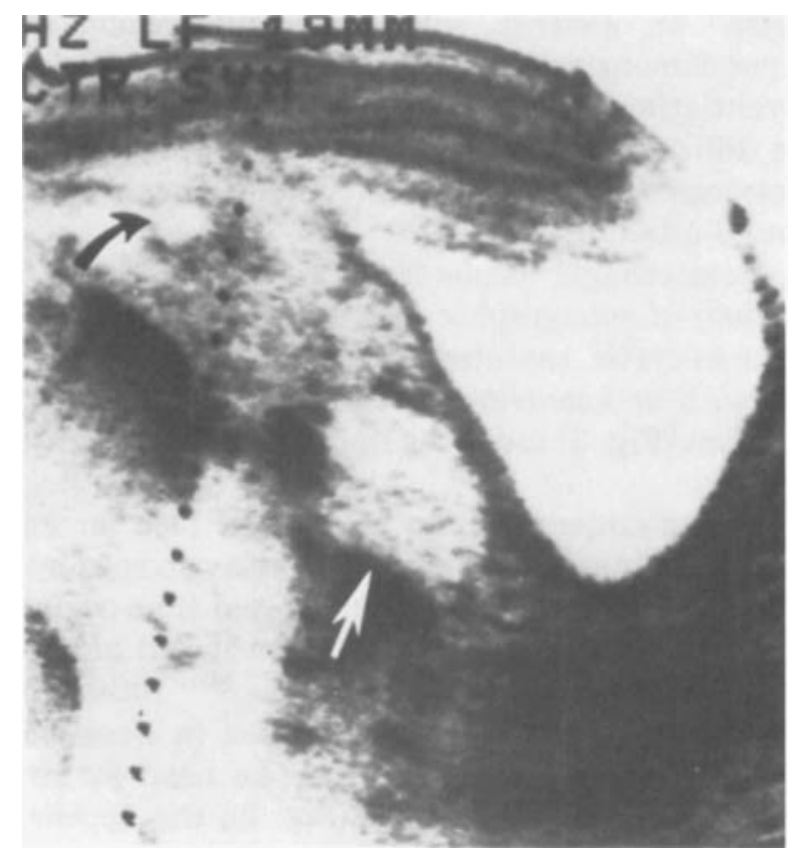

FIGUAE 5. Patient 5. Endometrioma, longitudinal scan: $6.5 \mathrm{~cm} \times 4$ $\mathrm{cm}$ mass with low-level echoes in the cul-de-sac (white arrow). Gestational sac in the uterine fundus (black arrow). ably resulting from chronic ovarian cystic disease and two previous left ovarian cystectomies. The disappearance of the mass on sonography 8 months after the initial sonogram was unexpected. We postulate that the inflammation associated with the chronic ovarian cystic disease may have subsided with hormonal therapy, which the patient received in the interim between the two sonographic examinations.

It is important to be aware that echogenic fluid-filled masses may simulate solid lesions. ${ }^{16}$ In particular, endometriomas and hemorrhagic corpus luteum cysts may simulate solid masses. However, careful attention to sonographic technique to elicit enhanced sound transmission should clarify the true liquid nature of such masses. In addition, refractive shadowing from the margins of the mass, when present, is an additional indicator of a fluid-filled mass. ${ }^{17}$

Of the seven patients with confirmation of the ultrasound findings, two patients (nos. 2 and 5) had repeat sonography during the course of pregnancy. In patient 5, the endometrioma decreased in size from $7 \mathrm{~cm}$ to $5 \mathrm{~cm}$ over a 2 -month interval. Although the symptoms of endometriosis often abate during pregnancy, ${ }^{18}$ the fate of endometriomas in general during pregnancy is unknown. As noted, in patient 2, the diagnosis became apparent after repeat sonography with water enema.

An important differential diagnostic consideration regarding echogenic adnexal masses dur- 


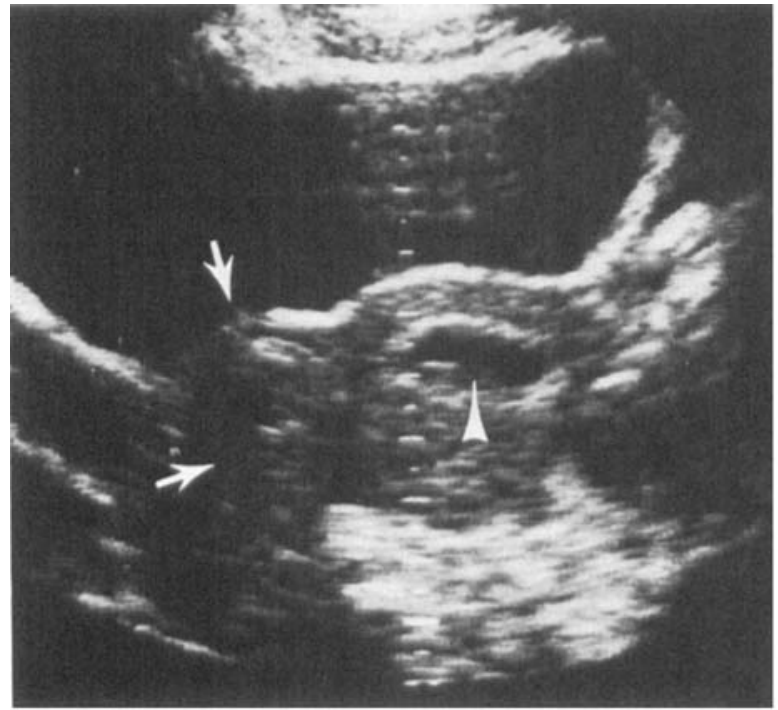

A

FIGURE 6. Right ectopic pregnancy. (A) Transverse scan. Poorly defined heterogeneous right adnexal mass (white arrows). Endometrial decidual response simulates a gestational sac with debris (arrowhead) resembling an embryo. (B) Sagittal sonogram. Heterogeneous echo texture and mass impression on the posterior aspect of the bladder by right ectopic pregnancy (arrows).

ing pregnancy is that of an ectopic pregnancy with associated endometrial decidual response ("pseudogestational sac"). ${ }^{19-21}$ In this situation, careful sonography and knowledge of the characteristic sonographic features of this entity, as well as other clinical data, should establish the diagnosis and the need for laparotomy. We encountered one patient who presented with an echogenic adnexal mass that proved to be an ectopic pregnancy at laparotomy. This particular mass (Fig. 6) was confused with an ovarian tumor, and the pseudogestational sac was misinterpreted as an intrauterine pregnancy because a structure resembling an embryo was identified (Fig. 6A).

Although our series is small, our experience indicates that a coexistent echogenic adnexal mass with an early intrauterine pregnancy is usually of a benign etiology and carries risk primarily related to the physical presence of the mass itself. Although an enlarging solid mass on sequential examinations might suggest neoplasia, ovarian neoplasms occurring during pregnancy are rare, and only a small percentage are malignant. Because of the spontaneous disappearance of the masses in two of the seven patients, the low risk of malignancy, and the risk of spontaneous abortion from surgery during early pregnancy, ${ }^{4}$ once an ectopic pregnancy is excluded, prudent observation and follow-up sonography are acceptable courses to follow.

\section{REFERENCES}

1. Miller EI, Thomas RH, Applegate JW: Persistent corpus luteum cyst of pregnancy: Sonographic

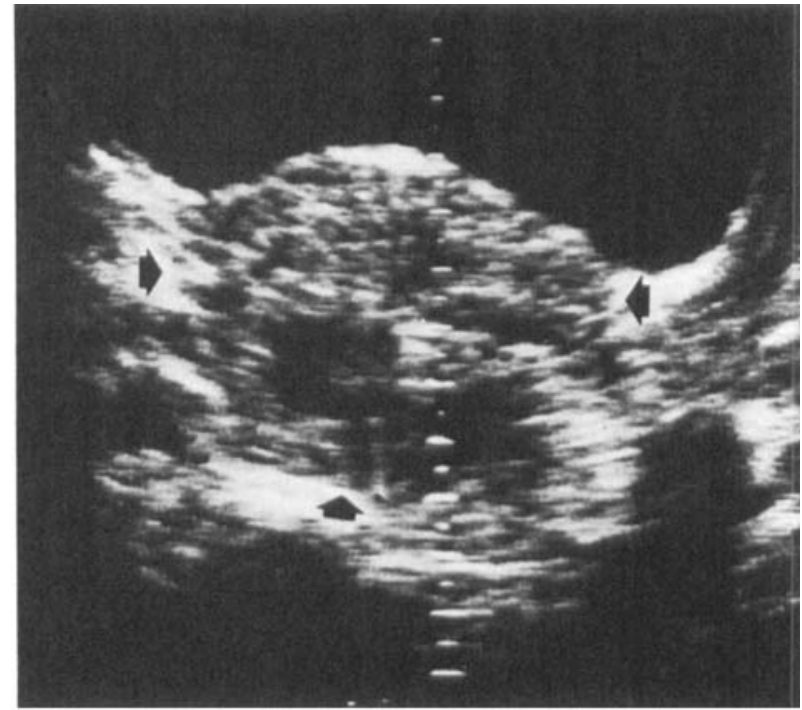

$B$ evaluation of cause of third trimester bleeding. $J$ Clin Ultrasound 6:187-188, 1978.

2. Lyons EA, Levi CS: Ultrasound in the first trimester of pregnancy, in Callen PW (ed): Ultrasonography in Obstetrics and Gynecology. Philadelphia, WB Saunders, 1983, p 13.

3. Donegan WL: Cancer and pregnancy. CA 33:194214, 1983.

4. Morrow PC, Hart WR: The ovaries, in Romney SL, Gray MJ, Little AB, et al (eds): Gynecology and Obstetrics: The Health Care of Women. New York, McGraw-Hill, 1975, p 1096.

5. Jubb ED: Primary ovarian carcinoma in pregnancy. Am J Obstet Gynecol 85:345-354, 1963.

6. Beischer NA, Buttery BW, Fortune DW, et al: Growth and malignancy: Ovarian tumors in pregnancy. Aust NZ J Obstet Gynecol 11:208-220, 1971.

7. Moyle JW, Rochester D, Sider L, et al: Sonography of ovarian tumors: Predictability of tumor type. Am J Roentgenol 141:985-991, 1983.

8. Walsh JW, Taylor KJW, Wasson JFM, et al: Gray scale ultrasound in 204 proved gynecologic masses: Accuracy and specific diagnostic criteria. Radiology 130:391-397, 1979.

9. Walsh JW, Taylor KJW, Rosenfield AT: Gray scale ultrasonography in the diagnosis of endometriosis and adenomyosis. Am $J$ Roentgenol 132:87-89, 1979.

10. Coleman BG, Arger PH, Mulhern CB: Endometriosis: Clinical and ultrasonic correlation. $A m J$ Roentgenol 132:747-749, 1979.

11. McGahan JP, Phillips HE, Oi RH: Coexistent endometriomas in pregnancy: Sonographic appearance. J Clin Ultrasound 10:180-182, 1982.

12. Scully RF, Galdabini JJ, McNeely BU (eds): Case Records of the Massachusetts General Hospital, Case 48;1979. N Engl J Med 301:1228-1233, 1979.

13. James AE, Conrad M, Millis J, et al: Ultrasound 
observations in the first trimester of pregnancy, in Sanders RC, James AE (eds): The Principles and Practice of Ultrasonography in Obstetrics and Gynecology. New York, Appleton-Century-Crofts, 1980, p 116.

14. Rubin C, Kurtz AB, Goldberg BB: Water enema: $A$ new ultrasound technique in defining pelvic anatomy. $J$ Clin Ultrasound 6:28-33, 1978.

15. Kurtz AB, Rubin CS, Kramer FL, et al: Ultrasound evaluation of the posterior pelvic compartment. Radiology 132:677-682, 1979.

16. Thurber LA, Cooperberg PL, Clement JG, et al: Echogenic fluid: A pitfall in the ultrasonic diagnosis of cystic lesions. $J$ Clin Ultrasound 7:273$278,1979$.

17. Robinson DE, Wilson LS, Kossoff G: Shadowing and enhancement in ultrasonic echograms by reflection and refraction. $J$ Clin Ultrasound 9:181188, 1981.

18. Novak ER, Woodruff JD: Gynecologic and Obstetric Pathology (ed 8). Philadelphia, WB Saunders, 1979, p 581.

19. Mueller CE: Intrauterine pseudogestational sac in ectopic pregnancy. $J$ Clin Ultrasound 7:133-136, 1979.

20. Marks WM, Filly RA, Callen PW, et al: The decidual cast of ectopic pregnancy: A confusing ultrasonographic appearance. Radiology 133:451454, 1979.

21. Mantoni M, Pedersen JF: Massive pseudogestational sac in ectopic pregnancy. J Clin Ultrasound 11:29-30, 1983. 